\title{
AVALIAÇÃO DE DANOS POR UMIDADE, EMSEMENTES DE SOJA, UTILIZANDO A TÉCNICA DA ANÁLISE DE IMAGENS ${ }^{1}$
}

\author{
TAÍS LEITE FERREIRA PINTO²; SÍLVIO MOURECICERO ${ }^{3}$; VICTOR AUGUSTOFORTI ${ }^{4}$
}

\begin{abstract}
RESUMO - Entre os problemas envolvidos na produção de sementes de soja destacam-se os danos por umidade, que resultam em perdas de germinação e de vigor. A técnica de análise de imagens, por meio do teste de raios X, é um método de precisão que possibilita examinar, com detalhes, a região danificada ou alterada, sua localização e extensão. Por ser um método não destrutivo, as sementes em análise podem ser submetidas a testes fisiológicos e, desta forma, é possível estabelecer as relações de causa e efeito. O presente trabalho teve como objetivo avaliar a eficiência da técnica de análise de imagens, por meio do teste de raios X, na identificação dos danos por umidade em sementes de soja, comparativamente ao teste de tetrazólio. Sementes de diferentes lotes de um mesmo cultivar (BRS 184) foram submetidas ao teste de raios $\mathrm{X}$ e, posteriormente, destinadas ao teste de primeira contagem de germinação, de forma a relacionar os danos com os possíveis prejuízos proporcionados às sementes. Paralelamente, foi realizado o teste de tetrazólio visando comparação com o teste de raios X. Para a análise interpretativa do teste de raios X, foram consideradas a severidade e a localização dos danos, juntamente com as fotografias digitais das plântulas ou sementes mortas resultantes do teste de primeira contagem de germinação. Com os resultados obtidos, pode-se afirmar que a análise de imagens mostrou-se eficiente na detecção dos danos por umidade em sementes de soja.
\end{abstract}

Termos para indexação: Teste de raios X, qualidade de sementes, Glycine max ( L.) Merrill.

\section{IMAGE ANALYSIS TECHNIQUE TOEVALUATE WEATHERING DAMAGE IN SOYBEAN SEEDS}

\begin{abstract}
Image analysis is a very promising technique to determine damage in seeds, which can result in germination and vigor losses. This precise method examines seeds individually using enlarged images in which damaged areas, as well their exact location and extension, can be found and examined in detail. Since this is a non-destructive method, analyzed seeds can be submitted to physiological tests to establish the relationship between damage and quality loss. The goal of this research was to study the efficiency of the image analysis technique, by the X-ray test, to identify weathering damage in soybean seeds, compared with the tetrazolium test. Seeds of different lots of soybean, cultivar BRS 184, were submitted to the X-ray test and, consecutively, used for the first count of the germination test, in order to determine the possible relationship between cause and effect. Simultaneously, the X-ray test was compared with the tetrazolium test. For the interpretation of X-ray test, the severity and location of weathering damage was considered. The results showed that image analysis, by the X-ray test, was efficient in detecting weathering damage in soybean seeds.
\end{abstract}

Index terms: X ray, seed quality, Glycine $\max$ ( L.) Merrill

\footnotetext{
1 Submetido em 10/11/2006. Aceito para a publicação em 12/03/2007. Parte da Dissertação de Mestrado apresentado pela primeira autora a USP/ ESALQ.

2 Eng. Agra ${ }^{a}$, Mestranda do Departamento de Produção Vegetal, USP/ESALQ, e-mail: tais_leite@yahoo.com

3 Eng. Agr ${ }^{\circ}$, Dr., Professor Titular, Departamento de Produção Vegetal, USP/ESALQ, Caixa postal 09, CEP 13.418-900, Piracicaba, e-mail: smcicero@esalq.usp.br

4 Aluno de graduação em Agronomia, USP/ESALQ, e-mail: vaforti@esalq.usp.br
} 


\section{INTRODUÇÃO}

O estabelecimento de uma lavoura com a população adequada de plantas é um dos fatores que mais contribui para assegurar o sucesso da produção e da obtenção de altos rendimentos e que depende, fortemente, da utilização de sementes de elevada qualidade. A utilização de sementes de soja com baixo vigor poderá tomar necessária nova semeadura, resultando em prejuízos aos produtores, particularmente em termos de aumento do custo de produção.

As sementes de soja, devido as suas características morfológicas e químicas, destacam-se por serem bastante sensíveis à ação de fatores do ambiente (Marcos Filho, 1979). A qualidade das sementes, principalmente em regiões tropicais, pode ser influenciada por diversos fatores que ocorrem em todas as etapas de produção. Dentre esses fatores destacam-se a deterioração por umidade.

A região tropical, devido ao clima predominantemente quente e úmido, propicia o desenvolvimento da deterioração por umidade, que é um dos fatores mais importantes que afetam a qualidade de sementes de soja (Krzyzanowski, 2004).

No ponto de maturidade fisiológica, o elevado teor de água das sementes e das vagens impede a execução da colheita mecânica. Assim sendo, as sementes devem permanecer no campo até a maturidade morfológica, período em que é atingido o teor de água adequado para a colheita mecânica. A fase compreendida entre a maturidade fisiológica e a morfológica, na qual as sementes permanecem no campo, pode ser considerada como um período de armazenagem e raramente as condições climáticas são favoráveis para tal (França Neto e Henning, 1984).

Conforme França Neto e Henning (1984), a deterioração das sementes no campo envolve alterações físicas, fisiológicas e sanitárias. A alteração física é ocasionada pelas sucessivas expansões e contrações do volume das sementes (decorrentes das oscilações de umidade e temperatura) que ocasionam a formação de rugas nos cotilédones, na região oposta ao hilo, devido à ausência da camada tegumentar composta por células em forma de "ampulheta" da hipoderme, de modo que as expansões e contrações não são atenuadas (Marcos Filho, 2005). Além disso, ocorre o cansaço físico dos tecidos, que pode resultar em ruptura do tegumento e dos tecidos embrionários, comprometendo o controle de permeabilidade das membranas aos níveis celular e sub-celular. Organelas, como os mitocôndrias, são particularmente afetadas por tal processo, havendo menor produção de energia (ATP), necessária para a germinação.

Sementes com tegumentos impermeáveis à água são menos afetadas pelas flutuações do conteúdo de água que podem ocorrer no campo quando se alternam períodos úmidos e secos, após a maturidade fisiológica (Potts et al., 1978).

Diante desta situação, é crescente a necessidade da utilização de métodos que permitam avaliar, de maneira ágil e eficiente, a qualidade fisiológica das sementes e, desta forma, possibilitar a tomada de decisões referentes à colheita, beneficiamento, armazenamento e comercialização.

$\mathrm{O}$ método de avaliação de sementes por raios $\mathrm{X}$ é simples, rápido, não destrutivo e eficiente para avaliação da morfologia de sementes que podem ou não terem sofrido mutação. Através da imagem de raios X é possível visualizar as estruturas da semente, identificando possíveis alterações, particularmente com referência ao eixo embrionário. A viabilidade das sementes submetidas ao comprimento de onda dos raios $\mathrm{X}$ não é comprometida devido às baixas intensidades utilizadas. (Bino et al.,1993 e ISTA, 1995).

Os efeitos de danos mecânicos na qualidade de sementes de milho foram avaliados pelas imagens digitais de raios $\mathrm{X}$ e conclui-se que a técnica pode ser utilizada para avaliar os danos mecânicos localizados externa e internamente nas sementes e foram diretamente relacionados com as anormalidades de plântulas ou com a morte dos embriões (Cicero et al., 1998).

Por meio da análise de imagens, foi possível detectar os danos mecânicos externos e internos em sementes de soja e observou-se que também é possível detectar os danos por percevejos e por umidade (Obando-Flor et al., 2004).

Desta maneira, o presente trabalho teve como objetivo avaliar a eficiência da técnica de análise de imagens, por meio do teste de raios $\mathrm{X}$, na identificação de danos por umidade em sementes de soja, comparativamente ao teste de tetrazólio. 


\section{MATERIAL E MÉTODOS}

A pesquisa foi conduzida nos Laboratórios de Análise de Imagens e de Análise de Sementes, do Departamento de Produção Vegetal, da Escola Superior de Agricultura "Luiz de Queiroz", Universidade de São Paulo (ESALQ/ USP), Piracicaba, SP e Laboratório de Análise de Sementes da Embrapa Soja, Londrina, PR.

Os tratamentos constituíram de sementes de soja de quatro lotes da cultivar, BRS 184, provenientes de Mauá da Serra, PR, da safra 2005/2006.

Para a determinação da qualidade inicial, as sementes dos quatro lotes foram submetidas à determinação do teor de água (BRASIL, 1992), germinação (BRASIL, 1992) e envelhecimento acelerado (Marcos Filho, 1999).

Para a detecção dos danos por umidade, as sementes foram submetidas ao teste de raios X. Duzentas e cinqüienta sementes (cinco repetições com 50 sementes), de cada lote, foram colocadas em alvéolos individualizados de uma placa acrílica, fixadas por baixo com fita adesiva transparente, mantendo-as posicionadas de maneira que o eixo embrionário ficasse situado paralelamente em relação à placa. $\mathrm{O}$ tempo de exposição e a intensidade de radiação utilizada foram de 25 kV e 40 segundos, respectivamente. Para a obtenção da radiografia, a placa de acrílico, com as sementes, foi colocada diretamente sobre um filme radiográfico (Kodak MIN-R 2000, tamanho de 18 x $24 \mathrm{~cm}$ ) à uma distância de $40 \mathrm{~cm}$ da fonte de radiação. $\mathrm{O}$ aparelho de raios $\mathrm{X}$ utilizado foi $\mathrm{o}$ Faxitron X-ray, modelo MX-20.

Os filmes radiográficos foram revelados em uma processadora automática Hope X-Ray, modelo 319 MicroMax. A seguir, as imagens dos filmes foram capturadas por um Scanner Umax modelo Power Look 1100, para a ampliação e melhor visualização em computador.

Com o intuito de avaliar a interferência dos danos por umidade detectados pela análise de imagens as sementes, previamente identificadas, foram submetidas ao teste de primeira contagem de germinação (Marcos Filho et al., 1987). A interpretação foi efetuada aos 5 dias após a semeadura, de acordo com as Regras para Análise de Sementes (BRASIL, 1992). Em seguida foram fotografadas individualmente todas as plântulas normais, anormais e as sementes que não germinaram, utilizando-se uma câmera digital Nikon, modelo D1, acoplada ao computador descrito anteriormente. Desta maneira, todas as imagens (raios X e plântulas ou sementes mortas) puderam ser examinadas simultaneamente na tela do monitor, permitindo fazer um diagnóstico para cada uma delas.

Os danos por umidade observados na análise radiográfica das sementes, receberam notas de acordo aos critérios contidos na Tabela 1, seguindo a classificação feita por Cícero et al. (1998) para sementes de milho e modificado para sementes de soja por Obando Flor et al. (2004).

Simultaneamente, foi realizado o teste de tetrazólio em amostras provenientes dos mesmos lotes, para posterior comparação entre os resultados. A condução do teste e a avaliação foram realizadas seguindo os critérios estabelecidos por França Neto et al. (1999).

Os resultados foram analisados de forma comparativa, procurando-se relacionar os referidos danos, detectados pela análise de imagens (semente por semente), com as possíveis anormalidades das plântulas ou sementes não germinadas.

O delineamento estatístico utilizado foi o inteiramente casualizado (quatro tratamentos com cinco repetições).

A análise foi realizada empregando o sistema SANEST para computadores (Zonta e Machado, 1984). Os dados referentes aos testes para a determinação da qualidade inicial (germinação, envelhecimento acelerado) foram transformados em arco seno da raiz quadrada de $\mathrm{x} / 100$. As médias foram comparadas pelo teste de Tukey com 5\% de probabilidade.

\section{RESULTADOS E DISCUSSÃO}

\section{Avaliação da qualidade inicial das sementes}

A análise comparativa dos dados relativos à avaliação da qualidade inicial das sementes em estudo indicou que os testes separaram, de maneira consistente, diferenças no potencial fisiológico dos lotes (Tabela 2). Assim, pode-se afirmar que sementes dos lotes 3 e 4 apresentaram potencial fisiológico superior ao das sementes dos lotes 1 e 2 .

\section{Avaliação de danos por umidade pela análise de imagens}

O exame simultâneo das imagens das sementes, obtidas pelo teste de raios X, e das plântulas, provenientes do teste de primeira contagem de germinação, permitiu proceder a um diagnóstico para cada caso estudado. 
TABELA 1. Notas atribuídas aos níveis de danos por umidade observados no eixo embrionário e nos cotilédones das sementes de soja através das imagens de raios $\mathrm{X}$.

Nível de dano

Não observado

Não severo

Severo
Eixo embrionário

Cotilédones

\begin{tabular}{cll}
\hline Não observado & 1 & 1 \\
Não severo & 2 & 2 \\
Severo & 3 & 3 \\
\hline
\end{tabular}

TABELA 2. Avaliação da qualidade inicial das sementes dos quatro lotes estudados: grau de umidade (GU), teste de germinação (TG) e envelhecimento acelerado (EA).

\begin{tabular}{cccc}
\hline Tratamentos & GU (\%) & TG (\%) & EA (\%) \\
\hline Lote 1 & 9,6 & $79 \mathrm{~b}$ & $65 \mathrm{~b}$ \\
Lote 2 & 9,9 & $81 \mathrm{~b}$ & $64 \mathrm{~b}$ \\
Lote 3 & 9,6 & $95 \mathrm{a}$ & $84 \mathrm{a}$ \\
Lote 4 & 10,0 & $94 \mathrm{a}$ & $82 \mathrm{a}$ \\
\hline CV (\%) & - & 4,1 & 7,2 \\
\hline
\end{tabular}

Na coluna, médias seguidas de letras diferentes diferem entre si pelo teste de Tukey a 5\% de probabilidade.

$\mathrm{Na}$ Tabela 3, encontram-se os valores referentes à intensidade de danos por umidade, nos quatro lotes, detectados pelo teste de raios X. Para os quatro lotes, verificou-se uma alta ocorrência do referido dano na categoria de danos não severos, tanto no eixo embrionário como nos cotilédones, porém, não foi verificada alta ocorrência para os danos considerados severos.

França Neto e Krzyzanowski (2000), Costa et al. (2001) e Costa et al. (2005) argumentaram que para as condições tropicais brasileiras, onde predominam altas temperaturas e excesso de chuvas no período de maturação da soja, as alternativas mais viáveis para produção de sementes de alta qualidade seria a escolha de regiões com altitude superior a $700 \mathrm{~m}$, onde predomina clima ameno e seco no período da maturação até a colheita. Tais considerações podem explicar a baixa ocorrência de danos por umidade classificados como severos nas sementes dos quatro lotes, pois as sementes utilizadas no presente estudo eram provenientes da região de Mauá da Serra, PR, que está localizada a aproximadamente $1000 \mathrm{~m}$ de altitude.

$\mathrm{Na}$ Tabela 4, são observadas as porcentagens de plântulas normais, anormais e sementes mortas, avaliadas pelo teste de primeira contagem de germinação, em sementes que apresentaram danos por umidade, avaliados pelo teste de raios X. Pelos resultados obtidos, verifica-se que os danos por umidade classificados com as notas 1.2. e 2.2. foram os que apresentaram maior ocorrência, porém, pouco interferiram na qualidade das sementes. $\mathrm{O}$ dano por umidade não foi a principal causa de perda de qualidade das sementes dos quatro lotes estudados, como pode ser observado nas porcentagens de plântulas anormais provenientes de sementes que apresentavam algum tipo de dano por umidade (danos não severos e, ou severos, presentes nas regiões do eixo embrionário e, ou cotilédones) que foram de $14 \%$ (lote 1), 3\% (lote 2), $0 \%$ (lote 3 ) e $3 \%$ (lote 4). Porém, é possível verificar na Tabela 4, que todas as sementes que apresentaram danos por umidade classificados como severos (maior ocorrência no lote 1), tanto no eixo embrionário quanto nos cotilédones (notas 2.3, 3.1, 3.2, e 3.3), resultaram em plântulas anormais.

Na Figura 1a, pode-se observar uma semente sem qualquer tipo de dano (nota 1.1.) que originou uma plântula normal (Figura 1b). 
TABEla 3. Porcentagens de sementes com diferentes intensidades de danos por umidade, no eixo embrionário e nos cotilédones, nos quatro lotes estudados, avaliadas por meio do teste de raios $\mathrm{X}$.

\begin{tabular}{ccccc}
\hline \multirow{2}{*}{ Local do Dano } & Lote & $1^{1}$ & $2^{2}$ & $3^{3}$ \\
\cline { 3 - 5 } & $\mathbf{1}$ & $78,4 \mathrm{a}^{*}$ & $20,0 \mathrm{a}$ & $1,6 \mathrm{a}$ \\
\multirow{3}{*}{ Eixo embrionário } & $\mathbf{2}$ & $71,6 \mathrm{a}$ & $27,2 \mathrm{a}$ & $1,2 \mathrm{a}$ \\
& $\mathbf{3}$ & $81,2 \mathrm{a}$ & $18,4 \mathrm{a}$ & $0,4 \mathrm{a}$ \\
& $\mathbf{4}$ & $81,2 \mathrm{a}$ & $17,6 \mathrm{a}$ & $1,6 \mathrm{a}$ \\
\hline C.V.(\%) & & 8,24 & 31,04 & 41,23 \\
\hline \multirow{2}{*}{ Cotilédones } & $\mathbf{1}$ & $67,6 \mathrm{a}$ & $30,8 \mathrm{a}$ & $1,6 \mathrm{a}$ \\
& $\mathbf{2}$ & $63,6 \mathrm{a}$ & $36,0 \mathrm{a}$ & $0,4 \mathrm{~b}$ \\
& $\mathbf{3}$ & $64,8 \mathrm{a}$ & $35,2 \mathrm{a}$ & $0,0 \mathrm{~b}$ \\
& $\mathbf{4}$ & $72,8 \mathrm{a}$ & $26,4 \mathrm{a}$ & $0,8 \mathrm{a}$ \\
\hline C.V.(\%) & & 8,35 & 17,7 & 42,37 \\
\hline
\end{tabular}

*Médias seguidas da mesma letra, na coluna e para cada local de dano, não diferem entre si pelo teste de Tukey a 5\% de probabilidade.

${ }^{1}$ Dano não observado; ${ }^{2}$ dano não severo; ${ }^{3}$ dano severo.

TABELA 4. Porcentagem de total (T) de sementes e porcentagens de plântulas normais (PN), de plântulas anormais (PA) e de sementes mortas $(\mathrm{M})$ no teste de germinação e as notas atribuídas às imagens de raios $\mathrm{X}$, para danos por umidade.

\begin{tabular}{|c|c|c|c|c|c|c|c|c|c|c|c|c|c|c|c|c|}
\hline \multirow[b]{2}{*}{ Nota* } & \multicolumn{4}{|c|}{ Lote 1} & \multicolumn{4}{|c|}{ Lote 2} & \multicolumn{4}{|c|}{ Lote 3} & \multicolumn{4}{|c|}{ Lote 4} \\
\hline & $\mathbf{T}$ & PN & PA & M & $\mathbf{T}$ & PN & PA & M & $\mathbf{T}$ & PN & PA & M & $\mathbf{T}$ & PN & PA & $\mathbf{M}$ \\
\hline 1.1. & 65 & 48 & 17 & 0 & 62 & 47 & 15 & 0 & 63 & 54 & 8 & 0 & 68 & 63 & 5 & 0 \\
\hline 1.2. & 13 & 11 & 2 & 0 & 11 & 11 & 0 & 0 & 18 & 18 & 0 & 0 & 13 & 13 & 0 & 0 \\
\hline 1.3. & 0 & 0 & 0 & 0 & 0 & 0 & 0 & 0 & 0 & 0 & 0 & 0 & 0 & 0 & 0 & 0 \\
\hline 2.1. & 2 & 2 & 0 & 0 & 2 & 2 & 0 & 0 & 2 & 2 & 0 & 0 & 4 & 4 & 0 & 0 \\
\hline 2.2 . & 17 & 17 & 0 & 0 & 24 & 24 & 0 & 0 & 16 & 16 & 0 & 0 & 14 & 14 & 0 & 0 \\
\hline 2.3. & 1 & 0 & 1 & 0 & 0 & 0 & 0 & 0 & 0 & 0 & 0 & 0 & 0 & 0 & 0 & 0 \\
\hline 3.1. & 1 & 0 & 1 & 0 & 0 & 0 & 0 & 0 & 0 & 0 & 0 & 0 & 1 & 0 & 1 & 0 \\
\hline 3.2. & 1 & 0 & 1 & 0 & 1 & 0 & 1 & 0 & 0 & 0 & 0 & 0 & 0 & 0 & 0 & 0 \\
\hline 3.3 & 0 & 0 & 0 & 0 & 0 & 0 & 0 & 0 & 0 & 0 & 0 & 0 & 0 & 0 & 0 & 0 \\
\hline Total & 100 & 78 & 22 & 0 & 100 & 84 & 16 & 0 & 100 & 90 & 10 & 0 & 100 & 94 & 6 & 0 \\
\hline
\end{tabular}

* 1. danos não observados, 2. danos não severos, 3. danos severos. O primeiro número da nota refere-se ao eixo embrionário e o segundo refere-se aos dos cotilédones. 

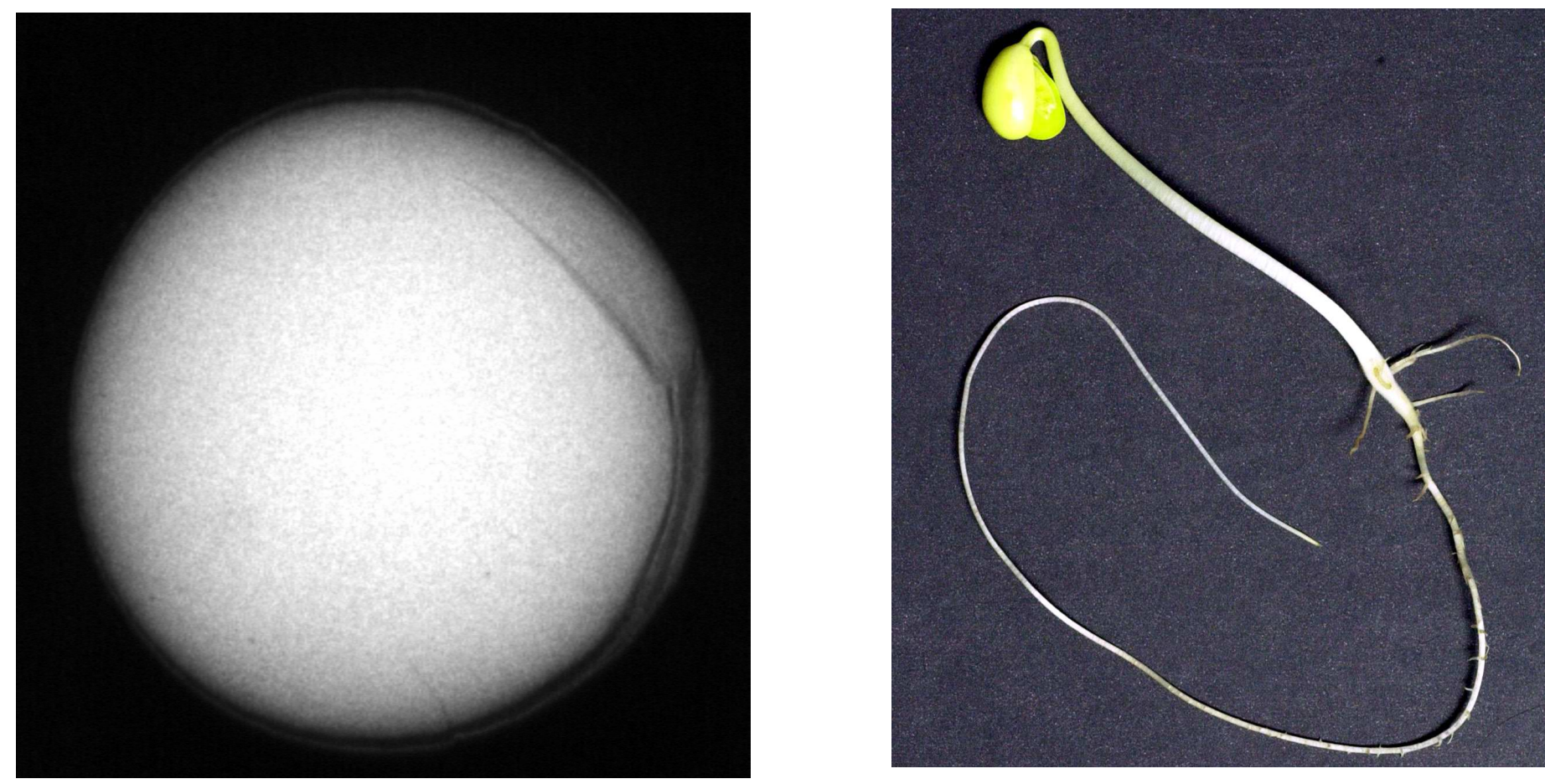

FIGURA 1 - Imagem de semente obtida por meio do teste de raios X, sem apresentar danos (a), nota 1.1, originando uma plântula normal (b).
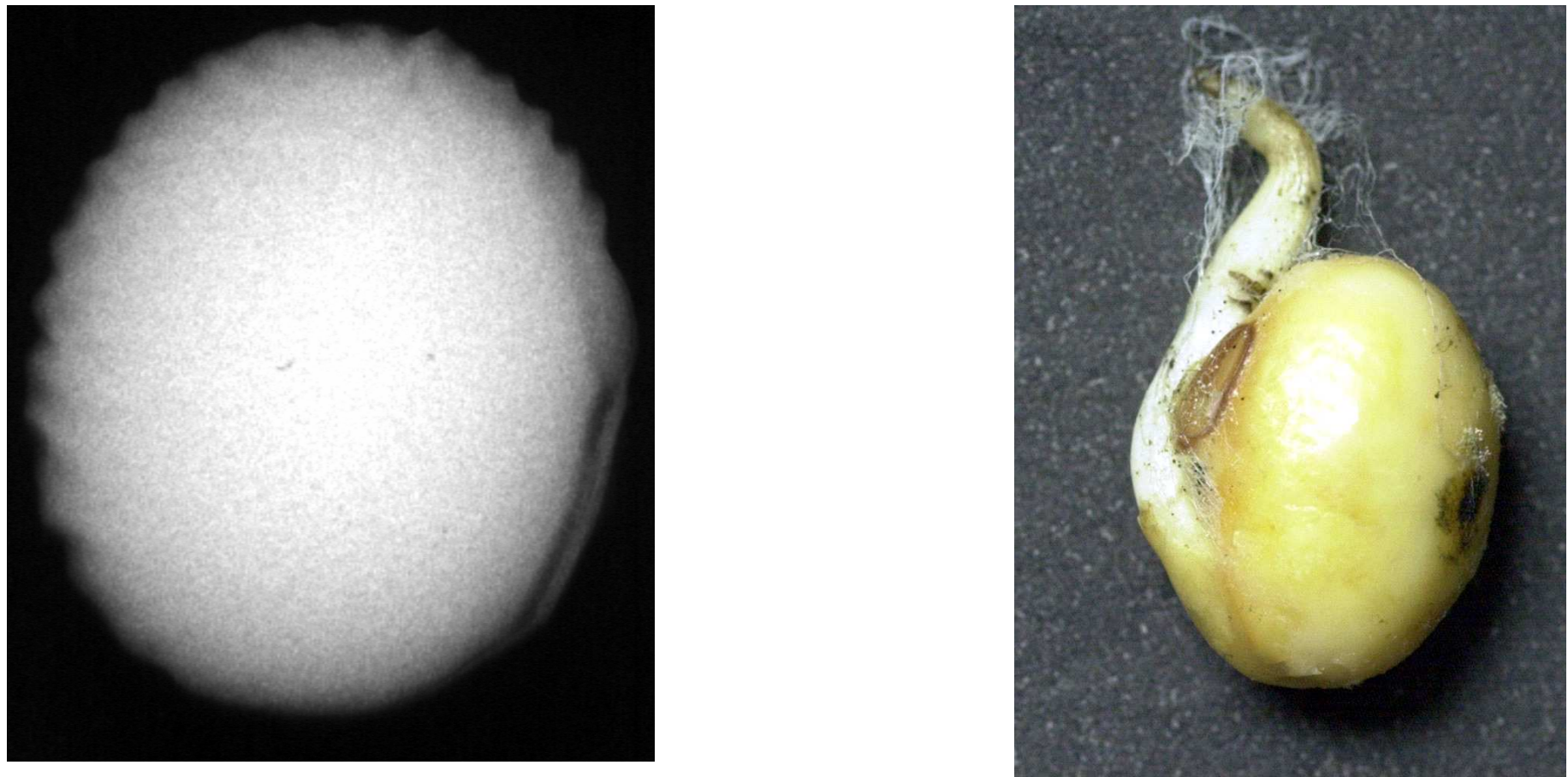

FIGURA 2. Imagem de semente obtida por meio do teste de raios $\mathrm{X}$, apresentando dano severo por umidade (nota 3.3), no eixo embrionário e nos cotilédones (a), originando uma plântula anormal (b). 
TABELA 5. Valores médios, em porcentagem, de danos por umidade (DU), classe 2 - 8 (danos totais), classe 6 - 8 (sementes inviáveis), vigor (classe 1 - 3) e viabilidade (classe 1 - 5). avaliados pelo teste de tetrazólio, nas sementes dos quatro lotes de soja.

\begin{tabular}{cccccc}
\hline & \multicolumn{2}{c}{ DU } & & Vigor & Viabilidade \\
\cline { 2 - 3 } \cline { 5 - 6 } Lote & $\mathbf{2 - 8}$ & $\mathbf{6 - 8}$ & & $\mathbf{1 - 3}$ & $\mathbf{1 - 5}$ \\
\cline { 2 - 3 } $\mathbf{1}$ & & & $\%$ & & \\
$\mathbf{n n n n n y y}$ & $93,6 \mathrm{a}^{*}$ & $1,6 \mathrm{a}$ & & $70,6 \mathrm{~b}$ & $82,4 \mathrm{~d}$ \\
$\mathbf{3}$ & $96,2 \mathrm{a}$ & $0,8 \mathrm{a}$ & & $74,2 \mathrm{~b}$ & $86,8 \mathrm{c}$ \\
$\mathbf{4}$ & $78,4 \mathrm{~b}$ & $0,2 \mathrm{a}$ & & $90,0 \mathrm{a}$ & $95,2 \mathrm{a}$ \\
\hline $\mathbf{C V}$ & $72,2 \mathrm{~b}$ & $1,0 \mathrm{a}$ & & $85,6 \mathrm{a}$ & $92,2 \mathrm{~b}$ \\
\hline
\end{tabular}

A Figura 2a, ilustra o dano por umidade classificado como severo tanto no eixo embrionário, como nos cotilédones (nota 3.3.), originando uma plântula anormal (Figura 2b). Segundo França Neto et al. (1999) sementes com deterioração por umidade apresentam rugas características nos cotilédones, na região oposta ao hilo, ou sobre o eixo embrionário. Também é possível verificar na Figura $2 b$ a presença de micélios fúngicos e, como destacado por França Neto e Krzyzanowski (2000), a deterioração no campo pode ser intensificada pela interação com alguns fungos, como Phomopsis spp. e Colletotrichum truncatum, que ao infectar as sementes, podem reduzir o vigor e a germinação das mesmas.

\section{Teste de tetrazólio}

Os dados referentes aos danos por umidade, vigor e viabilidade, avaliados pelo teste de tetrazólio, encontramse na Tabela 5. Os resultados de viabilidade e vigor obtidos confirmaram a diferença no potencial fisiológico das sementes dos lotes em estudo.

No total de danos por umidade (classes de 1-8) detectados pelo teste de tetrazólio, o mesmo apresentou, em valores absolutos, uma grande ocorrência, corroborando com os resultados obtidos pelo teste de raios $\mathrm{X}$. Observou-se maior porcentagem do referido dano nos lotes 1 e 2 em relação aos lotes 3 e 4 . Porém, para a classe de sementes não viáveis (6-8), verificou-se baixa ocorrência de danos e não houve diferença entre os lotes.

\section{Análise de Correlação}

Por meio do resultado do coeficiente de correlação linear (r), igual a 0,6963, verificou-se que existem correlações positivas entre os resultados de sementes com danos por umidade classificados como severos, obtidos pelos testes de raios $\mathrm{X}$, e os resultados de sementes com danos por umidade, presentes na classe de sementes inviáveis (classe 6-8), obtidos pelo teste de tetrazólio. Portanto, à medida que aumentam, proporcionalmente, sementes com danos por umidade, identificados pela análise de imagens e classificados como severos, aumentam, também, sementes com o referido dano, presentes nas classes 6-8 (sementes inviáveis), pelo teste do tetrazólio.

$\mathrm{O}$ baixo valor de $\mathrm{r}$ encontrado indica a existência de outros fatores envolvidos nas análises das sementes, os quais geralmente interagem fortemente e proporcionam redução gradual do r obtido, como também foi verificado por Costa et al. (2005).

$\mathrm{O}$ teste de raios $\mathrm{X}$, por ser um método não destrutivo, possibilita, após a radiação, a submissão das sementes a testes fisiológicos. Desta maneira, foi possível verificar a interferência dos danos por umidade detectados pela análise de imagens, por meio do teste de raios $\mathrm{X}$, no potencial fisiológico das sementes estudadas. Embora o porcentual de sementes com danos totais por umidade avaliado por meio do teste de tetrazólio (classe 2-8, Tabela 5) tenha sido mais elevado em relação ao teste de análise de imagens (sementes com notas 1.2 a 3.3, Tabela 4) constatou-se 
eficiência deste em detectar danos por umidade que afetam o potencial fisiológico das sementes, visto que os danos por umidade classificados como severos, pelo teste de raios $\mathrm{X}$, correlacionaram-se com a ocorrência de plântulas anormais (Tabela 4 e Figura 2) e também com os resultados de sementes inviáveis (classe 6-8) obtidos pelo teste de tetrazólio (Tabela 5). Portanto, é possível afirmar que a análise de imagens, por meio do teste de raios $\mathrm{X}$, surge como mais uma alternativa viável para avaliar danos por umidade em sementes de soja.

\section{CONCLUSÃO}

Os resultados obtidos indicam que a análise de imagens, por meio do teste de raios $\mathrm{X}$, permite identificar, com eficiência, danos por umidade em sementes de soja.

\section{AGRADECIMENTOS}

À Fundação de Amparo à Pesquisa do Estado de São Paulo (FAPESP) pela concessão de bolsa para a primeira autora.

À empresa Sementes Adriana e à Cooperativa Integrada, pela cessão das sementes.

\section{REFERÊNCIAS BIBLIOGRÁFICAS}

BINO, R.J.; AARTSE, J.W.; VAN DER BURG, W.J. Non destructive X-ray of Arabidopsis embryo mutants. Seed Science Research, Wallingford, v.3, p.167-170, 1993.

BRASIL. Ministério da Agricultura e Reforma Agrária. Regras para análise de sementes. Brasília: CLAV:DNDV:SNAD:MA. 1992.365p. CÍCERO, S. M.; VAN DER HEIJDEN, G.W.A.M., VAN DER BURG W.J., BINO, R.J. Evaluation of mechanical damages in seeds of maize (Zea mays L). by $\mathrm{X}$ ray and digital imaging. Seed Science and Technology, Zürich, v. 26, p. 603-612, 1998.

COSTA N. P.; MESQUITA C. M.; MAURINA A. C.; FRANÇA NETO J. B.; PEREIRA J. E.; BORDINGNON J. R.; KRZYZANOWSKI F. C.; HENNING A. A. Efeito da colheita mecânica da soja nas características físicas, fisiológicas e químicas das sementes em três estados do Brasil. Revista Brasileira de Sementes, Brasília, vol. 23, n.1, p.140-145, 2001.

COSTA, N.P.; MESQUITA, C.M.; MAURINA, A.C.; FRANÇA NETO, J.B.; KRZYZONOWSKI, F.C.; OLIVEIRA, M.C.N.; HENNING, A. A. Perfil dos aspectos físicos, fisiológicos e químicos de sementes de soja produzidas em seis regiões do
Brasil. Revista Brasileira de Sementes, Brasília, v. 27, n.2, p.0106, 2005.

FRANÇA NETO, J. de B. \& HENNING, A.A. Qualidade fisiológica e sanitária de sementes de soja. Londrina: EMBRAPA-CNPSo, 1984. 39p. (EMBRAPA-CNPSo. Circular Técnica, 09).

FRANÇA NETO, J.B.; KRZYZANOWSKI, F.C.; COSTA, N.P. Metodologia do teste de tetrazólio de sementes de soja. In: KRZYZANOWSKI, F.C.; VIEIRA, R.D.; FRANÇA NETO, J.B. (Eds.) Vigor de sementes: conceitos e testes. Londrina: ABRATES. 1999. cap.8, p.1-28.

FRANÇA NETO, J.B.; KRZYZANOWSKI, F.C. Produção de sementes de soja: fatores de campo. Seed News, Pelotas, n. 4, p. 20-23, 2000.

INTERNATIONAL SEED TESTING ASSOCIATION-ISTA. International rules for testing seed. Seed Science and Technology, Zurich, v.13, n.2, p.300-520, 1995.

KRZYZANOWSKI, F.C. Desafios tecnológicos para a produção de semente de soja na região tropical brasileira. In: WORLD RESEARCH CONFERENCE, 7.; INTERNATIONAL SOYBEAN PROCESSING, 4.; CONGRESSO BRASILEIRODESOJA, 3., 2004, Foz do Iguaçu. Proceedings... Foz do Iguaçu: EMBRAPA-CNPSo, 2004. p. 1324-1335.

MARCOS FILHO, J. Fisiologia de sementes de plantas cultivadas. 1.ed. Piracicaba: FEALQ, 2005.495p.

MARCOS FILHO, J. Qualidade fisiológica e maturação de sementes de soja (Glycine $\max$ (L.) Merrill). Piracicaba, 1979. 180f. Tese (Livre Docência) -Escola Superior da Agricultura "Luiz de Queiroz", Universidade de São Paulo, 1979.

MARCOS FILHO, J. Teste de envelhecimento acelerado. In: KRZYZANOWSKI, F.C.; VIEIRA, R.D.; FRANÇA NETO, J.B.(Ed.) Vigor de sementes: conceitos e testes. Londrina: ABRATES, 1999. cap.3, p.1-24.

MARCOS FILHO, J.; CÍCERO, S.M.; SILVA, W.R. da. Avaliação da qualidade das sementes. Piracicaba: FEALQ, 1987. 230p.

OBANDO-FLOR, E.P. Avaliação de danos mecânicos em sementes de soja por meio da análise de imagens. Piracicaba, 2003. 72f. Tese (Doutorado em Fitotecnia) - Escola Superior da Agricultura “Luiz de Queiroz”, Universidade de São Paulo, 2003.

OBANDO FLOR E.P.; CICERO S.M.; FRANÇA NETO J.B.; KRZYZANOWSKI F. C. Avaliação de danos mecânicos em sementes de soja por meio da análise de imagens. Revista Brasileira de Sementes, Brasília, v. 26, n1, p.68-76, 2004.

POTTS, H.C.; DUANGPATRA, J.; HAIRSTON, W.G.; DELOUCHE, J.C. Some influences of hardsleedness on soybean seed quality. Crop Science, Madison, v. 18, v.2, p. 221-224, 1978.

ZONTA, E.P.; MACHADO, A.A. Sistema de análise estatística para microcomputadores - SANEST. Pelotas: UFPel, 1984. (Registro SEI nº6606-0, Categoria AO). 